\title{
ATTITUDES TO MUSIC THERAPY AS A METHOD OF MAINTAINING PSYCHICAL HEALTH OF PEOPLE SUFFERING FROM PSYCHIATRIC DISORDERS
}

\author{
Diana Straksiene \\ Liuda Radzeviciene \\ Siauliai University, Lithuania
}

\begin{abstract}
The article presents the pilot research on the attitudes to music therapy of people who have psychiatric diseases. The attitudes were analyzed according to the preferred form of relax and leisure; information they have about the impact of music therapy on psychical health of individuals, expedience of music therapy for maintaining positive psychical health, the attitude to music therapy as a tool of personal empowerment and the preferred type of music of the respondents, the level of their music education, the type of music they used for relax activities, the meaning of music as a tool of therapy. It was revealed that music therapy is acceptable for the most of the respondents, nevertheless, there is lack of information for patients and applied activities of music therapy in the processes of treatment or rehabilitation.
\end{abstract}

Keywords: psychiatric patients, attitude, music therapy.

\section{Introduction}

During the last decades the entrenchment of humanistic and democratic values in our society impels to learn more about the effective ways to develop psychical wellness of people with psychiatric diseases. Modern medicine allows having shorter periods of hospitalization and it supports people with mentally diseases to keep closer relationships with community. However, even being out of hospitalization mentally impaired persons must keep some medical recommendations to prolong the periods of relapse. Therefore, the responsibility for their psychical health lays on the community, family, social services. Music therapy is one of the methods that could significantly affect psychic health of people suffering from psychiatric disorders (Ansdell, 2003, Catherin Carr et al., 2013). All forms of music may have therapeutic effects, although the music from one's own culture may be the most effective.

Styles of music differ in the types of neurological stimulation they evoke. Neuroscientific studies have shown music to be an agent capable of influencing complex neurobiological processes in the brain and suggest that it can potentially play an important role in treatment (Shuai-Ting Lin et al., 2011). Authors indicate that clinical studies provide some evidence that music therapy 
can be used as an alternative therapy in treating depression, autism, schizophrenia, and dementia, as well as problems of agitation, anxiety, sleeplessness, and substance misuse (ibid).

Music has great influence on individual's motor activity. It is known that persons suffering from psychiatric diseases mostly are passive (Gurevich et al., 2012; Elzbergaite, 2012) they spend their leisure preferring reading, watching TV, playing table games, etc. Music therapy helps patients to reduce muscle tension, achieve better muscle co-ordination, balance and strength, develop essential motor skills needed for holding and making use of objects (e.g. a beater), use rhythm to stimulate gross and fine motor movement e.g. dancing, jumping etc. (Gold et al., 2005; Peluso, et al., 2005, Elzbergaite, 2012).

Besides positive influence on motor activity it is expedient to apply music therapy for maintaining positive psychical health. The authors (McCaffrey et al., 2011; Ryan et al., 2012) emphasize improvement of self-image and group cohesiveness; increase of self-esteem verbalization and motivation; decreased anxiety/agitation.

Therefore, different approaches could be used applying music therapy for people with psychiatric illnesses. Restorative - using music to regain a skill or function, compensatory - using music to compensate for losses in conjunction with tools such as memory/communication aids and psycho-socio-emotional using music to enable emotional expression, engagement in social interaction and adjustment to disability (Covington, 2001; Keen, 2001; Nelson et al., 2001; Eyre, 2015).

The mentioned findings support bettering of psychical health and social empowerment that is a problematic area of social participation of persons suffering from psychiatric diseases. Empowerment is connected to a resourceoriented perspective on music therapy that implies a focus upon the client's strengths and potentials and emphasizes the importance of collaboration. The music became a powerful image that connected experiences in music therapy with challenges in real life (Rolvsjord, 2004). The current health promotion policy and practice emphasizes high value of community development work - it enables to identify problems, develop solutions and facilitate change (Mockeviciene, 2012). Theoretical exploration of the concept of empowerment (Randi Rolvsjord, 2004) together with its applicability to music therapy is another philosophical perspective because it focuses on positive changes in client's behavior, communication and self-beliefs.

The object of the research - attitudes to music therapy as a method of maintaining psychical health of people suffering from psychiatric disorders

The aim of the research is to reveal the attitudes to music therapy as a method of maintaining psychical health of people suffering from psychiatric disorders. 
Methods of the research: 1) analysis of research literature; 2) quantitative approach using closed type questionnaire, 3) descriptive statistics applying SPSS (Statistical Package for Social Sciences) program. Relations of demographic variable (gender) with dependent variables were checked with non-parametric test of Mann-Whitney criterion at the level of significance $p<=0,05$.

The questionnaire was composed according to the analysis of academic literature (Covington, 2001; Keen, 2004; Rolvsjord, 2004; Kardelis, 2002). The pilot research instrument consists of 15 questions that were divided into 5 diagnostic areas that could reveal the attitudes of people suffering from psychiatric diseases on the opportunity to apply music therapy in the process of rehabilitation.

1. Preferred form of relax and leisure

2. Information about the impact of music therapy on psychical health of individual

3. Expedience of music therapy for maintaining positive psychical health

4. Attitude to music therapy as a tool of personal empowerment

5. Preferred type of music of the respondents

The research was performed in 2014 in Šiauliai County. The quota of the research consists of 96 persons from 20 to 63 years of age, according to gender the respondents were 41 women and 55 men. The respondents' distribution according to age and gender corresponds to general demographic characteristics of Lithuania. The empirical data of the research was collected during the summer camp of people with different types of disabilities.

\section{Analysis of the results}

Understanding the high values of music therapy mentioned above it is presumable that in the process of rehabilitation music therapy could be applied widely maintaining person's psychical health in the period of remission. It was expedient to learn how much patients are involved with music in everyday life.

The main leisure activities of people suffering from psychiatric diseases were revealed (see Figure 1) in the pilot research.

Reading $(\mathrm{p}=0,035)$ and communication with others are the most popular forms of relax and leisure of people suffering from psychiatric diseases. Passive forms of relax could be attendant circumstances of the type of disability, individual characteristics of persons, or just life habits. Drawing as a tool of relax is used rarely but it must be mentioned that knitting, needlecraft, woodcraft was selected by $1 / 3$ of the respondents. The fact that people who are suffering from psychiatric diseases prefer passive leisure could indicate limited social environment, human or financial recourses. The same could be mentioned talking about sport activities. A small part of patients relax in sport activities. 
The analysis of empirical data shows that most popular type of psychical activity is basketball and tennis. Lack of physical activities, hypodynamia is common feature for people suffering from psychiatric diseases. This fact corresponds to the research by (Richardson et al., 2005) justifying those increasing exercise secondary symptoms such as low self-esteem and social withdrawal could also be alleviated. Individuals who engage in regular leisure-time activity of any intensity are less likely to have symptoms of depression (Harvey et al., 2010).

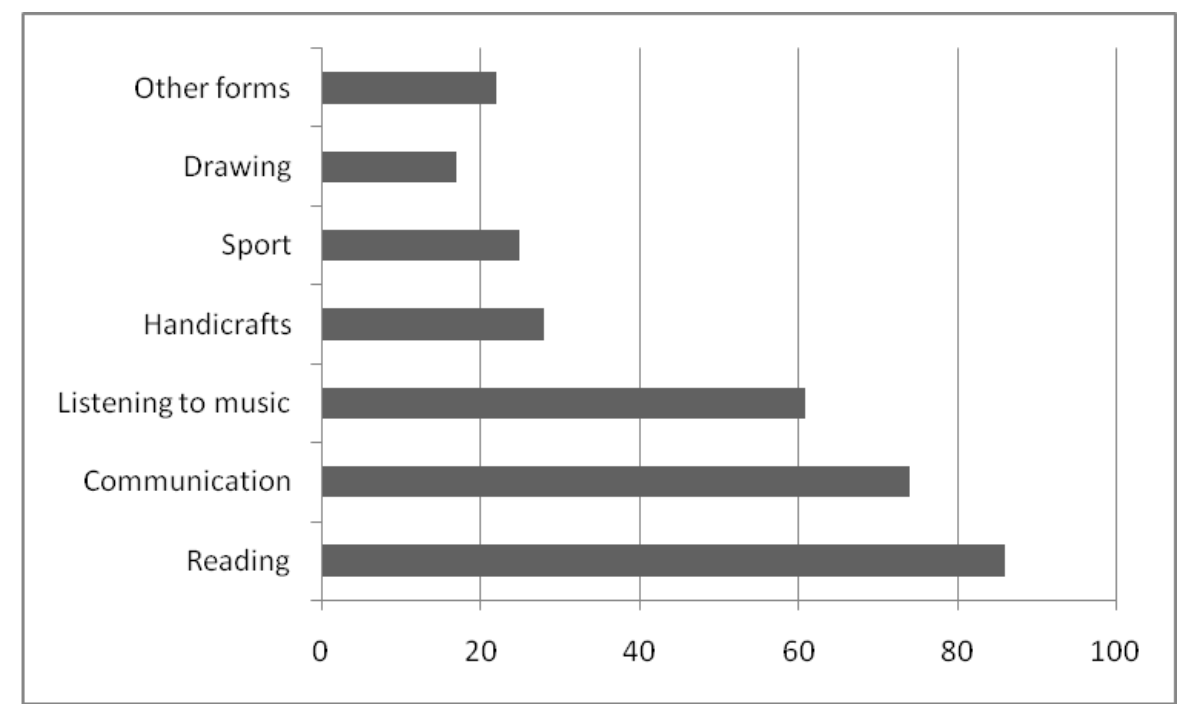

Figure 1 Preferred form of relax and leisure (\%)

Other types of relax such as taking care about pets, houseplants, hobbies were indicated. Harmful habits (usage of alcohol, gambling) were mentioned as well.

Listening to music is on the third place and it makes 61 per cent of all answers. It is an important fact talking about the process of rehabilitation, because for quite a large part of the participants' music therapy is an acceptable activity applying together with other alternative methods of influence. So for patients in the period of remission the conditions to develop music listening skills and motivation must be created in the nearest environment of the created opportunities to attend music therapy sessions in the community social services.

All the respondents have experience of hospitalization that is why they have some information about music therapy or even the experience in participating in it (see Figure 2).

Information about the impact of music therapy on psychical health of persons differs according to gender. Analyzing empirical data it was set up that men $(\mathrm{p}=0,020)$ need more information. The part of men who do not have any information about music therapy is larger as well. It could be explained in several aspects. Men are not so active and involved in the alternative 
Proceedings of the International Scientific Conference. Volume III, May $27^{\text {th }}-28^{\text {th }}$, 2016. 150-159

rehabilitation activities because it is the free choice of the patient. Women are likely to be more sensitive and more open to accept and to try different types of alternative rehabilitation. On the other hand, it could be associated with the experience they gained in hospital, the level of their own music education, individual traditions of their nearest environment.

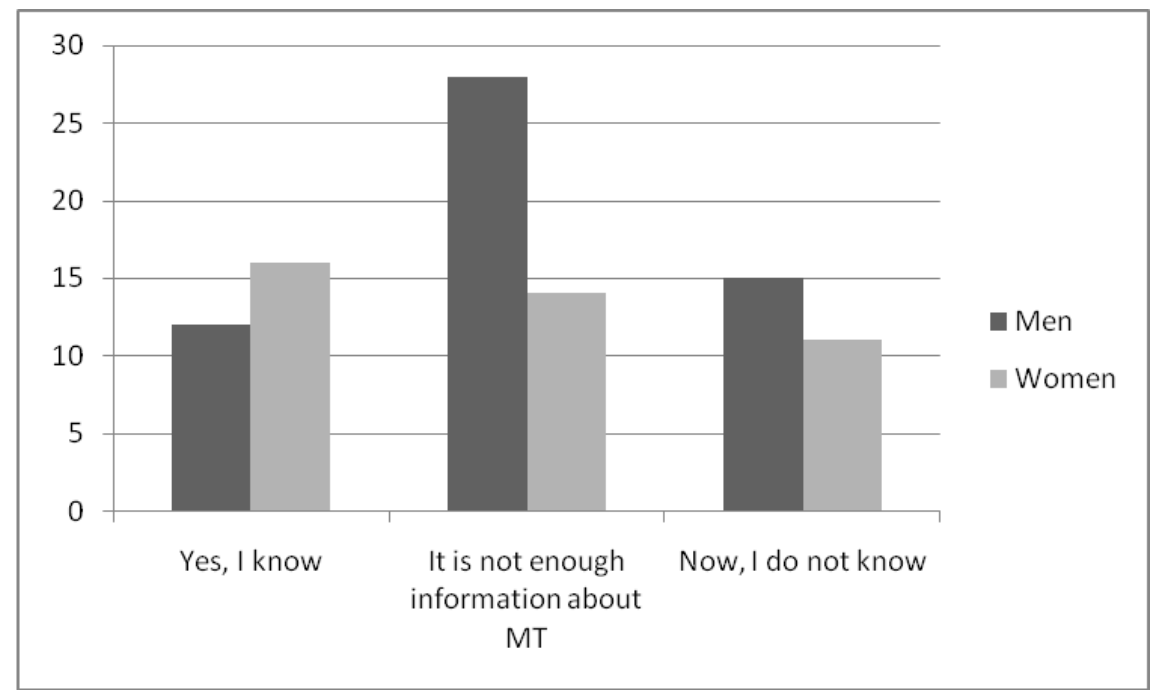

Figure 2 Information about the impact of music therapy on psychical health of individual $(\%)$

Knowing the level of information that individuals have about music therapy the expedience of alternative support for maintaining positive psychical health could be discussed. In spite of the fact that men have insufficient or even no information about music therapy they prefer to use it in the rehabilitation process during the period of remission.

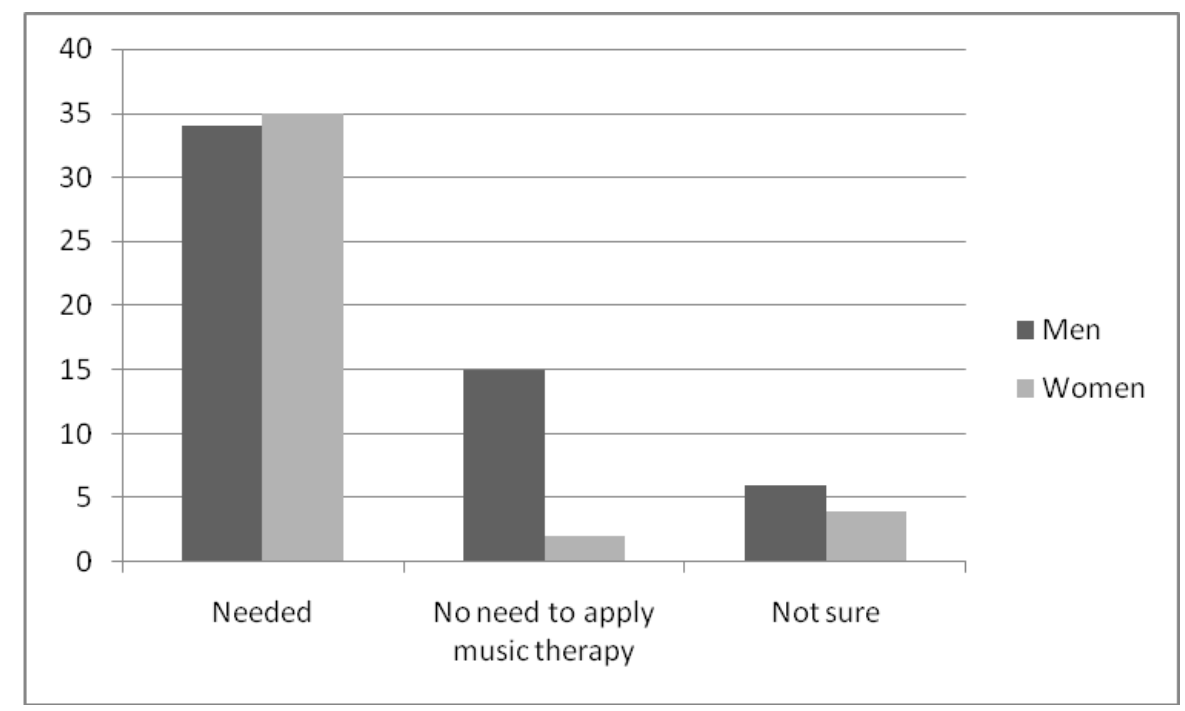

Figure 3 Expedience of music therapy for maintaining positive psychical health (\%) 
The results show that more than a half of the patients indicate music therapy as a desirable form of alternative rehabilitation $(\mathrm{p}=0,032)$. Analyzing the results according to gender it was set that men's attitude to the expedience of music therapy is more negative than women's $(\mathrm{p}=0,012)$. Nevertheless, the fact that listening to music is one of the most prevalent activities among people suffering from psychiatric diseases the programs of music therapy could be offered to social services, families as a kind of leisure, nearest social environment in which patients are integrated in the period of remission. Similar information is presented by Ansdell (2002). It is advisable to work with men more actively, to involve them into sessions of music therapy during the process of treatment, because refusing to participate in music therapy sessions they lose an opportunity to keep their psychical health more stable.

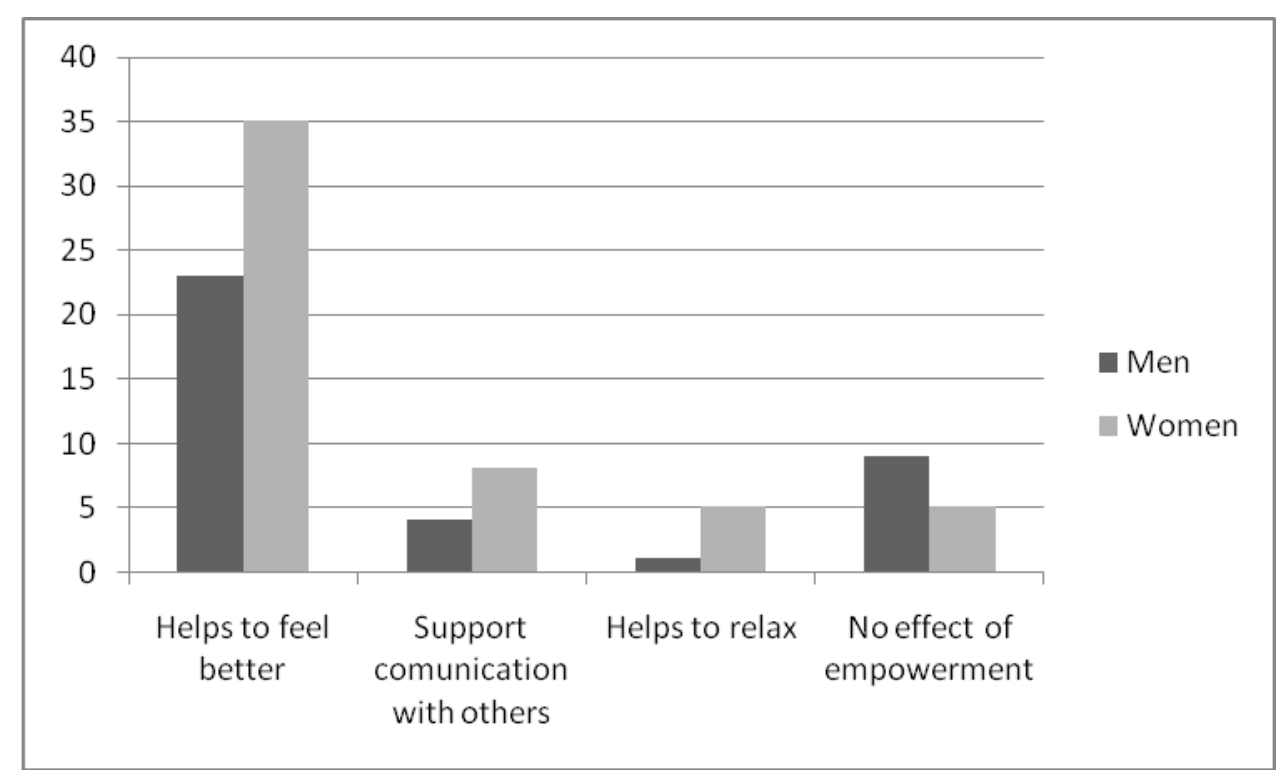

Figure 4 Attitude to music therapy as a tool of personal empowerment (\%)

The aspect of empowerment applying music therapy is widely discussed in theoretical and practical issues of social wellness of patients suffering from psychiatric diseases. Sometimes patients cannot describe exactly what effect of music therapy they expect, because some of them participated in the sessions of music therapy and the others did not. It was set that the largest part of the patients indicated that music therapy might help to feel better. To understand the expression "better" it must be discussed in more detail. The respondents in the term "better" include "positive emotions", "less sense of anxiety", "good sleep", "better appetite", etc. It means that general functioning of a person became more active and balanced. It would be useful to clarify what evidence of empowerment could be mentioned by people who have experience of music therapy. In this article the general data of patient's attitude to the music therapy 
as a tool of empowerment have been presented. Both men and women indicate that music therapy supports better personal feeling $(\mathrm{p}=0,015)$ comparing with other empowerment characteristics described in the questionnaire. The experience of self-sufficiency in the sessions of music therapy in women is expressed more than in men. These findings correspond to the thoughts of Silverman (2003), Smith et al., (2005) that music therapy as a tool for relax could be important for the creation and maintaining relationships with other people, because it significantly diminished patient's negative symptoms, increased ability to converse with others, reduced social isolation, and increased their level of interest in external events.

Rather unexpected result is that a large part of the respondents have no idea about the value of music therapy in the terms of empowerment. Research data indicate some ideas about application of music therapy as a tool of empowerment in the rehabilitation process of patients suffering from psychiatric diseases. In the first periods of rehabilitation music therapy could be applied like optional activity without higher goals of empowerment: self-confidence, critical thinking, and decision making skills (Brijunaite, 2007, Mockeviciene, 2012, Aleksiene, 2010).

The attitude to music therapy depends on the music education that patients could have. Those who have experience in music may understand the effect of music deeper and wider.

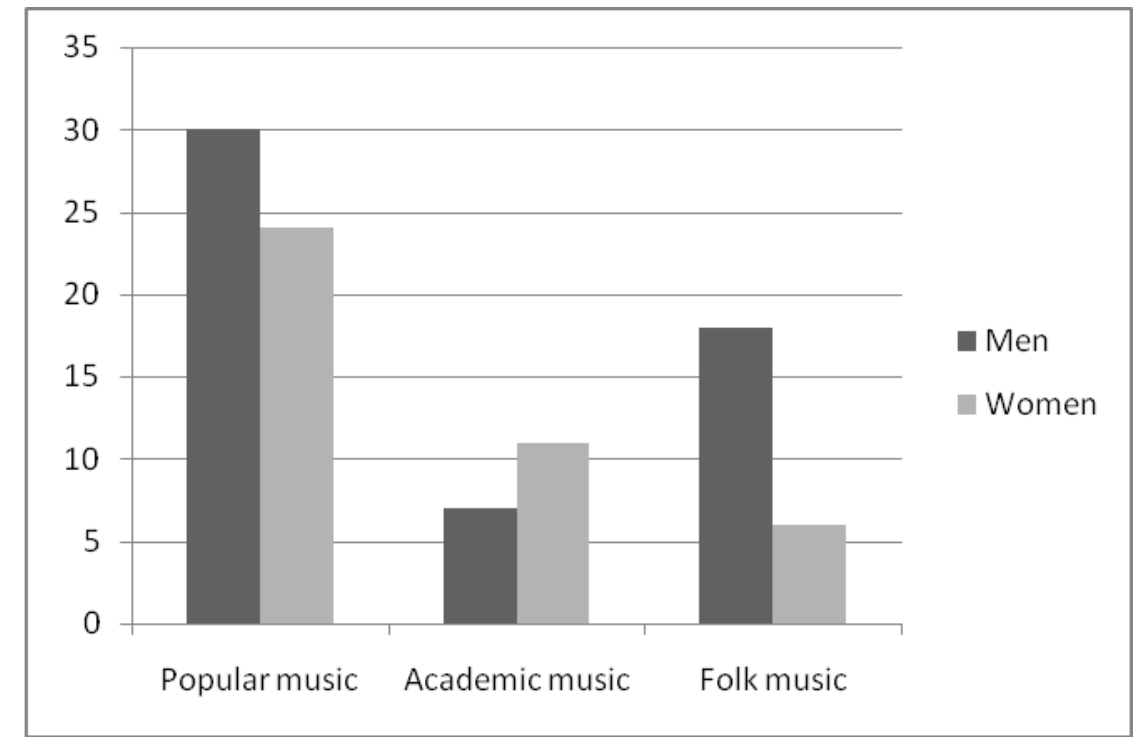

Figure 5 Preferred type of music of the respondents (\%)

Talking about the preference of music for music therapy sessions people suffering from psychiatric diseases indicate rather different types of music. The most preferred type is popular music. This kind of music is familiar to wide 
audience of population, it sounds on the radio and television, in concerts and celebrations. Therefore, for the research target group this kind of music is the most easily accessible. Significant differences comparing the preferences of folk music ( $p=0,023$ ) were set up in men's and women's attitude. It could be associated with the peculiarities of the Lithuanian folk music in which minor tunes prevail. Folk music being a part of ethnocultural heredity strongly affects person's psyche, even in the level of archetype. This may cause emotional dispirit, apathy, melancholy. This idea must be studied in more detail by empirical and theoretical analysis, but at the same time it indicates undeveloped opportunities of folk music as a tool of empowerment. The analysis of the research data shows extended reaches of psychological and cultural understanding of folk music.

Any significance was not found talking about the preference of classic music. The lack of acquaintance with classic music both among men and women could be mentioned as a tendency. These results could reflect general music sophistication, music culture in society, the development of music linking through media as well. Nevertheless, talking about music therapy it must be mentioned that popular music for this purpose is used quite rarely.

The research is composed according to the principles of research ethics and approved in Ethic Board of Faculty of Social Welfare and Disability Studies. All the participants gave their informed consent to participate in this study.

\section{Conclusions}

1. Analysis of scientific literature shows that music therapy is one of the methods that could significantly affect psychical health of people suffering from psychiatric disorders. Besides positive influence on motor activity it is expedient to apply music therapy for maintaining positive psychical health, improving self-image and group cohesiveness; increasing verbalization and motivation of self-esteem; reducing anxiety/agitation.

2. Reading and communication comparing with other types of activity are the most popular forms of leisure of people suffering from psychiatric diseases. Drawing as a tool of relax is used rarely but it must be mentioned that knitting, needlecraft, woodcraft was selected by $1 / 3$ of the respondents. Passive forms of relax could be attendant circumstances of the type of disability, individual characteristics of persons, or just life habits.

3. Men are not so active and involved in the alternative rehabilitation activities because it is the free choice of the patient. Women are likely to be more sensitive and more open to accept and to try different types of alternative rehabilitation. On the other hand, it could be associated with the 
experience they gained in hospital, the level of their own music education, individual traditions of their nearest environment.

4. Both men and women indicate that music therapy supports better personal feeling and self-confidence comparing with other empowerment characteristics. Experience of self-sufficiency in the sessions of music therapy was expressed in women more than in men.

5. Classic music is the least wanted type of music for therapy sessions among patients suffering from psychiatric diseases. It could be so because of the lack of the acquaintance with classic music both among men and women. The results could reflect general music sophistication, music culture in society, the development of music linking through media as well.

\section{References}

Aleksiene, V. (2010). Muzikos terapijos taikymas socialiniame darbe. I dalis. Teorija. Metodinè priemonè. Vilnius: VPU leidykla.

Ansdell, G. (2002). Community Music Therapy and the Winds of Change - A Discussion Paper. In: Kenny, Carolyn \& Stige, Brynjulf (Eds.). Contemporary Voices in Music Therapy. Oslo: Unipub Forlag.

Ansdell, G. (2003). The Stories We Tell. Some Meta-theoretical Reflections on Music Therapy. Nordic Journal of Music Therapy 12 (2), 152-159.

Brijunaite, R. (2007). Užimtumo terapija psichikos sutrikimu turintiems asmenims. Metodinè rekomendacija Vilnius, Socialinès apsaugos ir darbo ministerija.

Carr, C., Odell-Miler, H., \& Priebe, S. J. van Os (Ed.). (2013). A Systematic Review of Music Therapy Practice and Outcomes with Acute Adult Psychiatric In-Patients. PLoS One, 8 (8). DOI:10.1371/journal.pone.0070252 Retrieved from http://www.ncbi.nlm.nih.gov/ pmc/articles/PMC3732280/

Covington, H. (2001). Therapeutic music for patients with psychiatric disorders. Holist Nurs Practics. 15: 59-69.

Eyre, L. (2015). Music Therapy in Mental Health: Practice, Theory, Research, and Professional Perspectives. Music Therapy Perspectives Music Therapy Perspectives. DOI: $\quad 10.1093 / \mathrm{mtp} / \mathrm{miv} 029$. Retrieved from http://mtp.oxfordjournals.org/ content/early/2015/08/17/mtp.miv029.extract\#

Elzbergaite, A. (2012). Pagyvenusio ir senyvo amžiaus asmenu fizinio aktyvumo ir depresiškumo sqsajos. Magistro baigiamasis darbas. Kaunas. Retrieved from http://vddb.library.lt/fedora/get/LT-eLABa-0001:E.02 2012 D_20120620_16113558980

Gold, C., Heldal, T. O., Dahle, T., \& Wigram, T. (2005). Music Therapy for Schizophrenia or Schizophrenia-like Illnesses. The Cochrane Database of Systematic Reviews, DOI: 10.1002/14651858.CD004025. pub2. Retrieved from

http://onlinelibrary.wiley.com/doi/10.1002/14651858.CD004025.pub2/abstract

Gurevich, K. G., Burdukova, E. V., Pustovalov, D. A., \& Oranskaya, A. N. (2012). Overweight and Obesity Prevalence and Physical Activity among Moscow Schoolchildren. Journal of Health Science 2 (4): 23-28 DOI: 10.5923/j.health.20120204.01. Retrieved from http://article.sapub.org/10.5923. j.health.20120204.01.html 
Diana Straksiene, Liuda Radzeviciene. Attitudes to Music Therapy as a Method of Maintaining Psychical Health of People Suffering from Psychiatric Disorders

Harvey, S. B., Hotopf, M., Øverland, S., \& Mykletun, A. (2010). Physical activity and common mental disorders The British Journal of Psychiatry 197 (5) 357-364; DOI: 10.1192/bjp.bp.109.075176. Retrieved from http://bjp.rcpsych.org/content/197/5/357

Kardelis, K. (2002). Mokslinių tyrimu metodologija ir metodai. 2-asis leidimas, Siauliai. Siauliu universiteto leidykla.

Keen, A. W. (2004). Using Music as therapy tool to motivate troubled adolescents. Social Work Health Care. 39: 361-373.

Mockeviciene, A. (2012). Meno terapijos metodu taikymas socialiniame darbe. Seminaro dalomoji medžiaga. Klaipèda.

Monteiro, P. M. A., \& Silveira, G. A. L. H. (2005). Physical activity and mental health: the association between exercise and mood. Clinics 60 (1). São Paulo. Retrieved from http://dx.doi.org/10.1590/S1807-59322005000100012

McCaffrey, T., Edwards, J., \& Fannon, D. (2011). Is there a role for music therapy in the recovery approach in mental health? The Arts in Psychotherapy. 38 (3), 185-189. Elsevier Inc. DOI:10.1016/j.aip.2011.04.006. Retrieved from http://www.sciencedirect.com/science/article/pii/S0197455611000438

Nelson, G., Lord, J., \& Ochocka, J. (2011). Empowerment and Mental Health in Community: Narratives of Psychiatric Consumer/Survivors. Journal of Community \& Applied Social Psychology J. Community Appl. Soc. Psychol., 11: 125-142. DOI: 10.1002/casp.619

Ryan, P., Ramon, Sh., \& Greacen, T. (2012). Empowerment, Lifelong Learning and Recovery in Mental Health. Towards a New Paradigm. Palgrave Macmillan.

Richardson, C. R., Faulkner, G., McDevitt, J., Skinar, G. S., Hutchinson, D. S., \& Piette, J. D. (2005). Integrating Physical Activity into Mental Health Services for Persons with Serious Mental Illness. Psychiatric Services. A Journal of the American Psychiatric Association Editor: Howard H. Goldman, M. D., 56 (3), 324-331 Retrieved from http://dx.doi.org/10.1176/appi.ps.56.3.324

Rolvsjord, R. (2004). Therapy as Empowerment. InVoices: A World Forum for Music Therapy (ISSN 1504-1611) republished from Nordic Journal of Music Therapy 13 (2) 2004, 99-111. Retrieved from https://voices.no/index.php/voices/article/view/283/208

Silverman, M. J. (2003). The Influence of Music on the Symptoms of Psychosis: A MetaAnalysis. Journal of Music Therapy XL (1) 27-40.

Shuai-Ting, Lin, Pinchen, Yang, Chien-Yu-Lai, Yu-Yu, Su, Yi-Chun, Yet, Mei-Feng, Huang, \& Cheng-Chung, Chen (2011). Mental Health Implications of Music: Insight from Neuroscientific and Clinical Studies. Neuroscientific and Clinical Studies Harvard Review of Psychiatry 19 (1), 34-46. DOI: 10.3109/10673229.2011.549769. Retrieved from http://www.tandfonline.com/doi/abs/10.3109/10673229.2011.549769; access: 20151220

Smith, M., \& Buckwalter, K. (2005). Behaviors Associated with Dementia AJN, American Journal of Nursing July, 105 (7) 40-52. 